\title{
Historical redlining and contemporary racial disparities in neighborhood life expectancy
}

\author{
Nick Graetz $^{1 *}$, Michael Esposito ${ }^{2 *}$ \\ ${ }^{1}$ Department of Sociology, Princeton University \\ ${ }^{2}$ Department of Sociology, Washington University in St. Louis
}

\begin{abstract}
While evidence suggests a durable association between redlining and population health, we lack an empirical account of how this historical act of racialized violence produced contemporary inequities. In this paper, we use a mediation framework to evaluate how redlining grades influenced later life expectancy and the degree to which contemporary racialized disparities in life expectancy between Black working-class neighborhoods and white professional-class neighborhoods can be explained by past HOLC mapping. Life expectancy gaps between differently graded tracts are driven by urban renewal, economic isolation, and property valuation that developed within these areas in subsequent decades. Still, only a small fraction of the total disparity between contemporary Black and white neighborhoods is predicted by HOLC grades. We discuss the role of these maps in analyses of structural racism, positioning them as only one feature of the larger public-private project of conflating race with financial risk. Policy implications include targeting resources to formerly redlined neighborhoods, but also dismantling broader racist logics of capital accumulation codified in more abstracted political economies of place.
\end{abstract}

\section{Keywords:}

Structural racism, life expectancy, redlining, neighborhoods, mediation, decomposition

\section{* Corresponding authors:}

Nick Graetz, 106 Wallace Hall, Princeton, NJ, 08544, ngraetz@ princeton.edu.

Michael Esposito, 215 Seigle Hall, Washington University in St. Louis, St. Louis, MO, 63130, michaele@wustl.edu. 


\section{INTRODUCTION}

The strict delineation of neighborhoods, based on the perceived financial risk and social worth of their residents, represents a recurring form of racialized, structural violence in the United States. Perhaps the most expansive, systemized example of this type of violence was the national "redlining" project of the mid-20th century (Faber 2021). This practice was pivotal for codifying a central economic feature of structural racism - the conflation of "race" with "financial risk" and for the sociopolitical construction and reification of racial categories themselves. Although the racialization of place pre-dated the grading of neighborhoods by the Home Owners' Loan Corporation (HOLC), this institutional intervention helped to codify the notion that an area's current (and future) property value was proportional to its racial composition. By spatially marking neighborhoods as "undesirable" for mortgage lending through formal, state-sponsored policy, redlining helped to entrench racial segregation, facilitate the infusion of resources into white communities - through access to credit, home equity, and public investment - and legitimize the heaping of health hazards, dispossession, and displacement on communities of color, particularly Black neighborhoods (Fields and Raymond 2021).

Recently digitized HOLC maps (Nelson et al. n.d.) have allowed researchers to draw connections between historical redlining and various contemporary health indicators. Across the range of outcomes examined to date, the legacy of HOLC's hierarchical categorization of places is seemingly apparent: contemporary residents of areas that were once marked as Grade A generally experience better health than residents of places once coded as Grade D, despite decades of intermediate urban change. Still, despite this emerging evidence, there is some debate over the extent to which and how exactly HOLC maps generated place-based inequalities in contemporary health outcomes. We argue that these tensions revolve around distinctions between theoretical frameworks for how to measure and operationalize "redlining" as a historical exposure in quantitative research, including how to use historical data to approximate estimands that most clearly reflect social theories of how redlining produced contemporary inequity.

In this paper, we add to the discussion on how redlining measured via digitized HOLC maps can be implicated in contemporary place-based health disparities through two analyses. First, we examine how the spatial marking of neighborhoods as "desirable" or "hazardous" through HOLC maps - which serve as a proxy for the broader system of public-private partnerships behind New Deal and post-war era lending strategies_-led to different historical trajectories affecting contemporary life expectancy within those places. Second, we examine if and how these one-to-one historical trajectories predict large disparities in life expectancy across racialized communities today. Following neighborhoods over a century of change, we use the mediational g-formula to decompose the difference in contemporary life expectancy observed between formerly A-graded tracts and formerly D-graded tracts, attributing this disparity primarily to housing value inequities and stark racialized economic isolation that emerged among these places in later decades. We contextualize these findings by also demonstrating how this 
one-to-one neighborhood-level process explains only a small fraction of a total contemporary disparity between white- and Black-majority neighborhoods. Through this framework, we argue that redlining can be understood as both a distinct historical event in the durable racialization of place, but also as one part of a larger, structurally-embedded, racialized logic of current and future property valuation that is a fundamental determinant of population health today, influencing the racialized distribution of privileges and risks across even neighborhoods that were never explicitly evaluated by HOLC. We discuss how an emancipatory research and policy agenda must grapple not only with reparative policies for "formerly-redlined" neighborhoods, but also the more abstracted contemporary system of place-based capital accumulation built and maintained by these same racist redlining principles.

\section{BACKGROUND}

\section{The racialized construction of housing as an asset class}

In the 1930s, the New Deal laid the groundwork for massive public investment into a two-tiered housing system: 1) federally-backed mortgages and subsidies for private homeowners, especially for white communities, and 2) public housing, which over time became disproportionately occupied by people of color. In determining mortgage terms, U.S. cities partnered with the federally-sponsored Home Owners' Loan Corporation (HOLC) to develop a hierarchy of neighborhood spaces, ranging from "Grade A" to "Grade D," based on their suitability for investment by financial institutions (Rothstein 2017). The criteria underlying this classification scheme was blunt and highly racialized, such that areas inhabited by those racialized as "nonwhite" were systematically coded as "hazardous for investment" (i.e., Grade D).

This logic of racialized financial risk was not simply an artifact of deeply embedded racism amongst private real estate actors and public bureaucrats within HOLC, but also became structurally necessary for capital growth in a burgeoning market of private real estate; as Faber (2020) describes, "by conflating race with mortgage default risk and home equity growth, these policies not only justified racial discrimination, but also created a marketplace whose metrics of risk made discrimination necessary ... Although segregation is often considered to persist due to 'inertia,' [Krysan and Crowder 2017] suggest 'momentum' is a more accurate metaphor due to social processes resulting in the 'churning forward' of racially disparate residential mobility patterns ... HOLC's segregationist logic carried 'momentum' through subsequent federal and local policies as well as private institutions (e.g., mortgage lenders)" (Faber 2020, 744; Krysan and Crowder 2017). Indeed, a key feature of this process was active state intervention and public-private partnerships, both in building high-value white homeownership and equity via exclusionary practices (e.g., redlining maps evolving into algorithmic mortgage and appraisal practices, discrimination in lending, exclusionary zoning) and in predatory inclusion, whereby access to low-value homeownership was increasingly made available to Black communities 
through the expansion of credit on risky, exploitative terms (Robinson 2021; Taylor 2019)—or what Robinson (2020) refers to as the role of the state in "making markets on the margins."

The racist construction of the private housing market was a pivotal economic project in the social and political construction and reification of racial categories. Here local politics played an important role, often in tandem with the local interests of private real estate. As Sugrue (1997) describes in Detroit, reactionary white riots and violence during the 1940s and 1950s coalesced into homeowners' associations and neighborhood covenants, aided by the racist blockbusting strategies of real estate actors. Local governments were quick to bow to the pressure of homeowners' associations and real estate in failing to audit covenants or prosecute discriminatory behaviors under the 1968 Fair Housing Act (Sugrue 1997; Taylor 2019). These collaborations reflected a long history of strategic use of state apparatus by private real estate interests, who were also very active in sponsoring local politicians during the New Deal era. For example, profit-seeking within the racialized housing market may have been mitigated by an equally large federal investment in a true public option alongside the federally-backed private home mortgage. Indeed, the Labor Housing Conference social housing initiative (or "modern housing") was defeated during the 1930s through a combination of public-private partnerships in support of private real estate, which had ripple effects decades later: "A major postwar offensive against public housing mounted by real estate business groups that linked directly assisted construction with communism was an important impediment to the acceptance and growth of such programs ... Public and private entities fostered the notion, central to the neoliberal turn of the 1970 s, that equity is earned. Reforms to New Deal policy were seen as threats to Americans' "hard work" and "investments" in single-family homes, often with no acknowledgement of the subsidies and assistance from federal, state, and local governments making this possible, such as FHA structuring of the mortgage market, tax benefits, and infrastructure construction" (Radford 1996; 200; 204).

In all, "redlining" marshalled together a confluence of racist logics, across multiple public and private actors, that became deeply embedded within the construction of the modern two-tiered American housing market and fueled the racialized understanding of place. The era of statesanctioned redlining between the 1930s and the passage of the Fair Housing Act in 1968 indeed codified a racist theory of race and property value through multi-level public-private partnerships (e.g., FHA, HOLC, private real estate), leveraging the authority, legal power, and financial backing of the federal government to build a culture of "earned" (white) home ownership through massive public investment.

\section{Historical redlining, spatial marking, and contemporary population health}

Recently digitized HOLC maps (Nelson et al. n.d.) have allowed researchers to draw connections between historical redlining and a breadth of contemporary social outcomes, such as contemporary racial disparities in mortgage denials and subprime loans (Faber 2020; Faber 
2021). In many quantitative studies that leverage these data, HOLC maps are, at least implicitly, conceptualized as an indicator of the social and economic treatment that specific neighborhoods experienced under the structurally racist logics of credit and financing that predominated during the New Deal era. Indeed, in overlaying these historical maps with contemporary Census tract boundaries, researchers have been able to classify neighborhoods in such terms as "formerly A graded" or "formerly D graded"; use these categories to broadly summarize the racialized public and private investment strategies that a given neighborhood was subjected to under the scope of redlining; and connect these differential historical experiences — of being explicitly marked as "desirable" or "hazardous for investment" by the state during a crucial place-making momentto contemporary conditions within these same spaces.

Health researchers have been particularly busy linking past neighborhood redlining grades to present outcomes. As the geographer Ruth Wilson Gilmore (2007) states, structural racism is, at its core, "the state-sanctioned or extralegal production and exploitation of group-differentiated vulnerability to premature death." HOLC maps represent one such manifestation of this type of structural violence - organizing pre-existing forms of racial discrimination into official, statesponsored policy-leading researchers to investigate these institutionally enforced grades as possible generators of long-lasting, place-based disparities in morbidity and mortality. Contemporary health outcomes do appear to be associated with these historical labels: presentday residents of Grade A tracts have been shown to experience significantly better health than residents of Grade D tracts, along such indicators as late-stage cancer diagnosis (Krieger et al. 2020a); preterm birth (Krieger et al. 2020b); severe asthma-related outcomes (Nardone et al. 2020); self-rated health (McClure et al. 2019); poor mental health (Lynch et. al. 2021); and life expectancy (Richardson et al. 2020). The bulk of studies in this emerging field indeed align with the notion of HOLC mapping as a violent, state-sanctioned intervention that, despite nearly a century of change, is still implicated in the production of health and mortality within these same neighborhoods.

While this emerging evidence points to some durable association between redlining grades and contemporary health, there is considerable room to further interrogate the varied health legacies of this discrete act of racialized violence. One unanswered empirical question concerns the specific historical mechanisms that link redlining grades to contemporary place-based health outcomes. Prior work often implicates the spatial marking of places in these long-run effects, theorizing that the social meaning ascribed to neighborhoods via HOLC persisted well beyond the initial intervention to stratify and segment neighborhoods across subsequent decades (Faber 2021; Faber 2020). Put differently, scholars argue that the institutionalized interpretation of Grade A neighborhoods as places that are "valuable" and "worth investment" and of Grade D neighborhoods as places that are "lesser" and "hazardous for investment" became embedded in subsequent systems distributing privileges and harms, in ways that motivated both private and public actors to perpetually layer resources onto $\mathrm{A}$ areas and risks onto $\mathrm{D}$ areas, culminating in significant spatialized health inequity across time (Krieger et. al. 2020b). 
Although a spatial-marking framework is conceptually compelling for explaining how redlining produced contemporary population health, we currently lack a careful empirical account of this idea, one that traces the historical trajectories of Grade A and Grade D neighborhoods across time and identifies how these disparate histories shape current place-based health disparities. It is important to document the specific structural (mediating) pathways through which redlining grades shaped neighborhoods over the decades leading up to and following the 1968 Fair Housing Act; doing so situates "redlining" as not simply a static historical exposure, but rather as part of a dynamic process that continues to be embedded in the spatial distribution of contemporary risks and privileges. As we will discuss below, this empirical task has important theoretical implications for how we situate redlining within contemporary stratification and an agenda of restorative justice: not only in focusing on the "direct effect" of historical redlining, but also in the specific, mediating exposures that have been distributed by redlining.

Given this perspective, we pose the following empirical hypothesis:

- Spatial marking: Census tracts graded as D in 1935-1940 followed substantially different historical trajectories of urban renewal, school segregation, property valuation, and racialized economic isolation than tracts graded as A, resulting in differential period life expectancy in 2018.

\section{Redlining and structural racism}

While disentangling how the historical pathways triggered by explicit HOLC mapping unfolded onto contemporary outcomes within the same tract is an important empirical task, we might also contextualize the legacy of redlining grades by considering how much of the total disparity in outcomes across the contemporary geography of race and class can be predicted by a spatial marking perspective. Redlining was not only part of a larger project of racial dispossession (e.g., mortgage terms and denial), but also of displacement (e.g., "urban renewal," eviction, foreclosure) (Faber 2021; Fields and Raymond 2021) — and these segregationist logics were subsequently codified within broader, national systems of housing financialization following deindustrialization and the shift of capital from manufacturing to real estate (Sugrue 1997; Taylor 2019).

In light of these broad place-making processes, the degree to which we can pin the history of displacement and dispossession brought about directly from being spatially marked by HOLC to contemporary racialized health disparities is called into question. Indeed, as we demonstrate below, 70\% of the most concentrated Black working-class neighborhoods in 2015-2019 are not located in Census tracts that were once graded as D. And yet these areas that were never formally marked as "hazardous for investment" by HOLC still face systematic isolation, devaluation, and, consequently, disproportionate exposure to risk factors that structure the racialized health disparities that we observe today - including state violence, environmental hazards, and exploitative conditions under segmented labor and housing markets (Sewell 2016; Sugrue 1997; 
Taylor 2019). Redlining may have played a role in constructing contemporary conditions in these spaces by fueling broader, punitive, anti-Black segregationist logics that spilled across all geographies, but the extent to which we can leverage the direct, one-to-one historical experience of being negatively marked by HOLC in predicting outcomes across contemporary racialized neighborhoods is uncertain.

When taken in context, the spatial marking of neighborhoods by HOLC was only one manifestation of the broader redlining project of codifying a racist theory of value that conflated "race" with "financial risk" - a logic that shaped the historical and contemporary practice of public-private partnerships in real estate long after the 1968 Fair Housing Act and extending beyond the one-to-one matching of historical and contemporary land areas. Given this perspective, we pose a second empirical hypothesis:

- Structural perspective: There is an immense gap in life expectancy between Black working-class tracts and white professional tracts in 2015-2019 and only a small portion of this is predicted by tract-level HOLC grades in 1935-1940.

As we discuss below, empirical support for this hypothesis would not suggest that redlining is unimportant in describing the contemporary distribution of premature mortality. Rather, as long noted by historians, geographers, and sociologists theorizing structural racism and racial capitalism, the ramifications of this broader project extend far beyond the original HOLC maps into the more abstracted systems of finance and appraisal governing the racialized dual mortgage market today (Dantzler 2021; Fields and Raymond 2021; Howell and Korver-Glenn 2018; Rugh and Massey 2010; Sewell 2016; Sugrue 1997; Taylor 2019; Zaimi 2020).

\section{Present study}

In this study, we build upon our understanding of how redlining influenced present-day population health inequalities through a mediation framework (Wang and Arah 2015). Using this approach, we test the two hypotheses above to identify concrete mechanisms through which the spatial marking of redlining (measured with HOLC) operated over time to influence population health, but also whether this one-to-one process connecting historical to contemporary land area explains only a small portion of a total racialized disparity in period life expectancy. We find evidence for both hypotheses: there is a significant difference in life expectancy between A and $\mathrm{D}$ tracts which can be traced along the axes of urban renewal projects, school segregation, property valuation, and racial isolation that occurred in the decades following redlining. Still, there is a much larger difference in life expectancy between all concentrated Black working-class and white professional-class neighborhoods today, only a small fraction of which is predicted by the one-to-one matching of HOLC grades to contemporary tracts. We discuss the implications for social and health policy, considering the equitable targeting of resources to formerly redlined neighborhoods, but also the larger project of dismantling racist logics of capital accumulation now codified in the broader political economy of place distributing risk of premature mortality. 


\section{DATA AND METHODS}

We use a counterfactual mediation approach (the parametric mediational g-formula) to trace connections between historical legacies of redlining and the contemporary distribution of tractlevel period life expectancy, as illustrated in the directed acyclic diagram (DAG) in Figure 1. These ordered mediators, spanning from 1930-2018, proxy four broad dynamics through which redlining may have built enduring racialized and place-based vulnerabilities to premature death:

1. Racialized public-private investment: Redlining was one instrument within the broader project of racialized public-private investment during the New Deal and post-war era. Importantly, these efforts triggered a decades-long process of not only entrenching existing racial segregation, but also of building groundwork for new systems of displacement (Field and Raymond 2021; Nelson and Ayers n.d.). Here we consider how redlining is linked to subsequent, so-called "urban renewal" projects in "undesirable" neighborhoods, which displaced thousands of Black families and connected to durable white-Black school and residential segregation.

2. Racialized valuation of place: The turn to federal subsidies in private (white) homeownership and the massive expansion of profiteering in the real estate industry necessitated the conflation of "race" and "financial risk," deepening the social and political construction of racial categories (Faber 2020; Fields and Raymond 2021; Sewell 2016; Taylor 2019). This entanglement accelerated during the period of deindustrialization and suburbanization as capital shifted from manufacturing to real estate (Howell and Korver-Glenn 2020; Sugrue 1997). Indeed, today the financialization of housing increasingly shapes both anti-Black dispossession (e.g., the ability to build equity, property taxes) and displacement (foreclosures, evictions) (Fields and Raymond 2021). Here we consider how redlining, including through its connection to urban renewal and school segregation, ultimately influenced the distribution of property valuation in the early 21 st century.

3. Racialized "selection" into place: This political economy of place intersected with the racialized organization of the real estate industry to produce extreme and durable segregation of Black communities, particularly low-income populations (Sharkey 2013; Taylor 2019). In this way, the legacies of redlining have been an important feature in not only perpetuating racist systems' distributed risks and privileges, but also in reifying racial categories (Sewell 2016). Here we consider the reciprocal relation through which Black working-class communities continued to be steered, after redlining, towards lowvalue property and how property valuation continued to be linked to the racial composition of neighborhoods (Howell and Korver-Glenn 2018).

4. The racialized and classed production of premature mortality: The distribution of mortality risk in the population is co-constituted with the historical legacies of place, in 
contrast to conceptual models of population health that treat characteristics such as income and home ownership as individual-level risk factors. Rather, these place-based relations to segmented labor and housing markets, as well as access to affordable and quality healthcare, are predicated on a long history of racism in the political economy of place, including contributions from redlining (Dantzler 2021; Laster Pirtle 2020; Logan and Molotch 1987; McClure et al. 2020).

\section{Data and variables}

[Figure 1 here]

To build the scaffolding of this historical process (Figure 1), we draw on data for the following variables: (1) Census tract-level HOLC redlining grades (1935-40; A-D), (2) county-level total urban renewal projects (1955-66; log), (3) school segregation at the district-level (1990; continuous Black vs. white index of concentration at the extreme [ICE]), (4) tract-level home values (2006; log), (5) tract-level race-class segregation (2015-2019; continuous Black workingclass vs. white professional class ICE ), and (6) tract-level period life expectancy (2018; continuous). We define "working-class" and "professional-class" using the crude occupational tabulations at the tract-level (Appendix Table 1). We use this variable to draw attention to a fundamental cause (class relations), rather than more proximal determinants (household income), of health, though these measures are highly correlated $\left(\mathrm{R}^{2}=0.87\right.$ nationally).

In our first analysis of spatial marking, we construct two samples following Krieger et. al. (2020b): all tracts with more than half of their land area covered by a D-graded polygon $(n=3,196)$ and all tracts with more than half of their land area covered by an A-graded polygon $(\mathrm{n}=632)$. In our second analysis from a structural perspective, we also construct two samples: all tracts in the top 5\% nationally of the 2015-2019 race-class ICE ("Black working-class"; $\mathrm{n}=3,776$ ) and all tracts in the bottom 5\% ("White professional-class"; $n=3,147$ ). To capture the full variation of redlining grades as a mediator in the second analysis, we include HOLC grade as a continuous indicator (average of overlapping grades weighted by geographic area covered; other $=0, A=1, B=2, C=3, D=4)$ - though multinomial and binary $(D=1$, other=0) mediators produce similar results.

Following (Faber 2020) we also include a set of pre-treatment confounders at the county-level from the 1930 Census: percent Black, percent foreign-born, unemployment rate, population size, median home value, and the Black-white homeownership ratio. Additional information on all data sources is available in Appendix Table 1.

\section{Statistical analysis}

We focus our mediation analyses on the following questions: 
R1. A forward-facing counterfactual frame, which asks how the spatial marking of places (1935-1940) translated into historical trajectories influencing period life expectancy in those places (2018). In other words, we might consider that redlining is a place-based exposure, and we want to measure its marginal effect on contemporary life expectancy (e.g., considering if tracts graded as A instead had experienced the historical trajectories of tracts graded as D).

R2. A backward counterfactual frame, which asks how much of the disparity in 2018 life expectancy across 2015-2019 White professional-class neighborhoods and 2015-2019 Black working-class neighborhoods is predicted by 1935-1940 HOLC grades. In other words, we might consider that the one-to-one redlining of neighborhoods is but one cause of the historical production of the total racialized disparity in place-based life expectancy we observe today.

These related counterfactual frames help to identify the place-based mechanisms underlying the long-run effects of HOLC mapping on contemporary life expectancy (R1), but also explore to what extent a total racialized gap in tract-level contemporary life expectancy can be traced backwards to historical, tract-level redlining grades (R2) (Gelman and Imbens 2013; Schwartz, Gatto, and Campbell 2016). This second frame is important to consider in parallel with the first, as roughly $70 \%$ of hyper-segregated Black working-class communities today live within neighborhoods that were never marked as grade D (Figure 1).

We use the mediational g-formula to consider three estimands in each of our analyses:

1. The controlled direct effect $(C D E)$ : The exposure is related to the outcome through pathways outside of the observed mediators; this has also been called the "counterfactual disparity measure" (Naimi et al. 2016).

2. The pure indirect effect (PIE): The exposure is related to the mediator, and the mediator then influences the outcome in ways that do not depend on the exposure.

3. The proportion attributable to interaction (PAI): The exposure is related to the mediator, and the mediator then influences the outcome in ways that $d o$ depend on the exposure.

Beyond the more conventional question of whether redlining exerts some residual influence on outcomes outside of more proximal historical mediators (CDE), these estimands also reflect on whether redlining influenced the distribution of subsequent systems (PIE) and whether redlining also influenced the relationship between those systems and outcomes (PAI).

\section{Estimation}

Conventional regression, controlling for post-treatment characteristics, assumes that there exists no exposure-induced mediator-outcome confounding; in other words, that the cross-world 
independence assumption holds (VanderWeele 2014). In such approaches, the counterfactual comparison is between two populations that vary on exposure status (e.g., being marked as Grade A vs Grade D by HOLC), assuming nothing else changes across the populations over time. Previous research has demonstrated that this assumption is untenable in the quantitative study of complex social processes, where systems of exposure likely affect virtually all other observed variables over time (Jackson and VanderWeele 2019; Naimi et al. 2016; Wodtke, Harding, and Elwert 2011).

The "g-formula" is a generalization of standardization that allows for the estimation of unconfounded summary effects without relying on the restrictive cross-world independence assumption inherent to conventional regression estimators. The g-formula was developed in the formal quantitative causal inference literature and is flexible for estimating any counterfactual contrast (Robins 1986; Wang and Arah 2015). Equation 1 illustrates the population mean health outcome, $E[Y]$, standardized across all values of an exposure variable, $X$ (e.g., being graded as "D" within the historical system governing the distribution of $Y$, period life expectancy).

$$
E[Y]=\sum_{x} P(Y=y \mid X=x) P(X=x)
$$

This generalized formula, or "g-formula," for the mean outcome can be extended over all stratifying variables, $V$, which confound the association between $X$ and $Y$, as well as variables which mediate the association, $M$ (i.e., fall along the causal pathway). We use $P(x)$ as shorthand for $P(X=x), P(v)$ as shorthand for $P(V=v)$, etc. In Equation 2, we illustrate the g-formula for the expectation of $Y$ given exposure level $X=x$.

$$
E\left[Y^{x}\right]=\sum_{m} P(Y \mid x, \boldsymbol{m}, \boldsymbol{v}) P(\boldsymbol{m} \mid x, \boldsymbol{v}) P(\boldsymbol{v})
$$

In Equation 3 we consider a specific mediator $M$ which is causally dependent on a vector of previous mediators $L$. We use the following notation with respect to a specific mediator:

- $Y=2018$ period life expectancy (continuous).

- $X=1935-1940$ redlining grade $\left(x=\right.$ "A", $x^{*}=$ "D").

- $M=$ specific mediator (e.g., race-class index of concentration at the extremes in 2015$2019)$ with an exposure interaction affecting $Y\left(m=\right.$ index value, $m^{*}=$ reference value $)$.

- $L=$ vector of other historical mediators (e.g., median home values in 2006) with exposure interactions in affecting $Y\left(l=\right.$ index value, $l^{*}=$ reference value $)$ and that also confound the effect of $M$ on $Y$. 
- $V=$ vector of pre-treatment confounders in 1930: percent Black, percent foreign-born, unemployment rate, population size, median home value, and the Black-white homeownership ratio.

$$
E\left[Y^{x}\right]=\sum_{m} \sum_{l} P(Y \mid x, \boldsymbol{m}, \boldsymbol{l}, \boldsymbol{v}) P(\boldsymbol{m} \mid x, \boldsymbol{l}, \boldsymbol{v}) P(\boldsymbol{l} \mid x, \boldsymbol{v}) P(\boldsymbol{v})
$$

When considering the effect on $Y$ of changes to $X$ via a specific mediator $M$, variables in $L$ are referred to as "exposure-induced mediator-outcome confounders" because they are affected by the exposure and confound the relationship between $M$ and $Y$ (Wang and Arah 2015). The presence of such confounding means that we cannot estimate the counterfactual associated with a given value of $X$ while holding $L$ constant (as in conventional regression or matching estimators, e.g., Baron-Kenny mediation), because such a world would be impossible to observe. In terms of our theoretical framework, this reflects on the critiques discussed above: what would it mean to consider the effect of being grade as D vs. A without anything else changing? At best, this approach involves describing a marginal counterfactual that is difficult to interpret because changing this exposure requires considering changes in everything else that is influenced by redlining. At worst, this approach reifies the notion that historical processes are static exposures that can be considered separately and independent from other factors (Kohler-Hausmann 2019; Zuberi and Bonilla-Silva 2008).

Total effects calculated via g-computation are analogous to effects obtained by marginal structural models (Robins, Hernán, and Brumback 2000; Wodtke, Harding, and Elwert 2011). However, the g-formula provides a straightforward decomposition of this total effect or disparity into additive direct, interactive, and indirect pathways of accumulation via multiple mediators. This extension of g-computation to causal mediation and effect decomposition is described by Wang and Arah (2015) (considering one mediator with an exposure interaction) and Daniel et al. (2015) (considering multiple dependent mediators, but no exposure interactions). We extend the decomposition in Wang and Arah (2015) to include multiple dependent mediators with exposure interactions affecting both the outcome and each other. The difference between $E[Y \mid x]$ and $E\left[Y \mid x^{*}\right]$ (i.e, the total observed disparity between A and D neighborhoods) can be decomposed into the controlled direct effect (CDE; effects via unobserved mediating pathways), the proportion attributable to interaction via each mediator $M$ (PAI; discrimination in the underlying system connecting $M$ to $Y$ ), and the pure indirect effect via each mediator $M$ (PIE; emergent effects due to the compositional change in $M$ and its main effect on $Y$ ) (Reskin 2012; Wang and Arah 2015).

- $C D E_{M=m^{*}}=E\left[Y_{x m^{*}}\right]-E\left[Y_{x^{*} m^{*}}\right]$

- $P A I^{(M)}=E\left[\left(Y_{x m}-Y_{x^{*} m}-Y_{x m^{*}}+Y_{x^{*} m^{*}}\right)\left(M_{x}\right)\right]$

- $P I E^{(M)}=E\left[Y_{x^{*} m}\left(M_{x}\right)\right]-E\left[Y_{x^{*} m}\left(M_{x^{*}}\right)\right]$ 
The CDE is evaluated at the reference values for all mediators that are interacted with $X$ in affecting the outcome. This decomposition will therefore result in one CDE, one PIE for each mediator, and one PAI for each interacted mediator (for mediators that do not have an exposure interaction in affecting $Y$, the PAI defined above will equal zero) that add up exactly to the observed disparity in period life expectancy (or total effect). This requires estimating multiple expected values for $Y$ via simulation using the g-formula in Equation 3. This is achieved via stochastic cohort simulation, which involves the following general steps. First, we fit a generalized linear model for each mediator and the outcome. We then repeat the decomposition algorithm below 1000 times to propagate uncertainty to final effect estimates, which are summarized by the means and $95 \%$ intervals of those 1000 estimates:

1. Draw a random multivariate-normal sample of parameters from all models using fitted coefficients and variance-covariance matrices.

2. Create 30 replicates of the 50 multiply imputed datasets to remove Monte Carlo error arising from stochastic individual-level response prediction.

3. Simulate a counterfactual course for the tracts graded as D by predicting forward with the sample of parameter estimates (i.e., What if these tracts had followed the same historical trajectories as those graded as A along all observed mediating systems?).

4. Use values from observed data and the counterfactual course to calculate all necessary expected values for effect decomposition using the g-formula in Equation 3.

5. Calculate the $C D E_{M=m^{*}}$, the $P A I^{(M)}$ for each mediator, and the $P I E^{(M)}$ for each mediator using expected values obtained above.

Two types of non-random missing data may result in biased effect estimates: item-nonresponse and censoring of observations. We create 30 multiply imputed datasets using chained equations to account for missing observations due to item-nonresponse (van Buuren and GroothuisOudshoorn 2011). G-formula simulations begin with the full sample in the first wave and every individual is simulated through all subsequent waves. In effect calculations, we are then including all simulated person-years that were censored in the survey sample. This is analogous to the approach used in marginal structural models to correct for non-random censoring biasing effect calculations (VanderWeele 2009).

It is important to note that decomposed effects given a relatively simple g-formula can be nonparametrically identified. With enough data and if all variables were low dimension (e.g., binary), we could simply calculate the entire conditional probability space using empirical population proportions. However, this possibility quickly breaks down in the presence of more than a few variables, especially if any are continuous, and the use of data from samples (with associated uncertainty) rather than full populations. For this reason, we model the full conditional probability space using the observed data and use these modeled parameters to simulate the "parametric g-formula" used in the effect decomposition above (Keil et al. 2014). 
We specify a generalized linear model for each mediating variable and outcome variable, $Y$, taking the general form:

$$
Y_{i}=\beta_{0}+\beta_{1}\left(M_{i} * X_{i}\right)+\beta_{2}\left(V_{i}\right)+\varepsilon_{i}
$$

Models are indexed by individual ( $i$ ). Models parameterize each mediator and the outcome with appropriate likelihoods (normal, binomial) and link functions (identity, logit) given the structure of each dependent variable $\left(Y_{i}, M_{i}\right)$.

\section{Implementation}

All analysis is conducted using $\mathrm{R}$ 4.0.2. The data used here from the Zillow home value time series are not made available, but all code and analogous examples are available at https://github.com/[ADD]. Additionally, the highly accessible CMAverse $\mathrm{R}$ package provides similar g-formula estimators for the CDE, PAI, and PIE, though only accounting for one mediator or joint set of mediators at a time (i.e., all other possible mediating pathways are moved to the CDE rather than estimated separately): https://bs1125.github.io/CMAverse/articles/overview.html.

\section{RESULTS}

[Figure 2 here]

We first present descriptive statistics across the two samples in our spatial marking analysis (R1; $\mathrm{D}$ tracts vs. A tracts) and the two samples in our analysis from a structural perspective (R2; Black working-class tracts vs. white professional-class tracts) in Figure 2. We observe that roughly $30 \%$ of the most concentrated Black working-class tracts are situated in areas that were once graded as D, compared with $13 \%$ of white professional-class tracts. Across all mediators, the gap between tracts formerly graded as D and A is smaller than the gap between contemporary Black working-class and white professional-class tracts. We also observe stark inequalities in life expectancy within these comparison groups: on average, the difference in 2018 life expectancy between A and D tracts was 5.95 years (95\% confidence interval: 5.59-6.36), while the difference in 2018 life expectancy between Black-working class and white-professional class tracts was 9.14 years (95\% CI: 8.94-9.35).

We next turn to the results of our forward-facing mediation analysis (R1), which traces the historical trajectories of tracts that were spatially marked as Grade D compared to Grade A overtime and estimates how these histories contributed to disparities in contemporary life expectancy within these spaces. Figure 3 displays the results of this first analysis.

[Figure 3 here] 
The first three panels of Figure 3 demonstrate the historical trajectories that Grade A and Grade D tracts followed after being spatially marked by HOLC in the 1930s. Here, we observe the following features: (1) tracts that were marked as Grade D experienced elevated levels of subsequent school segregation compared to tracts that were marked as Grade A-though D graded tracts in areas that participated in more urban renewal projects tended to have less racially isolated schools [Figure 3; Panel 1]; (2) tracts that were marked as Grade D in the 1930s experienced much lower levels of property valuation in later decades compared to tracts marked as Grade A [Figure 3; Panel 2]; and (3) Grade D tracts displayed much higher levels of contemporary racialized and classed isolation than Grade A tracts, with part of this association being mediated through school segregation and housing valuation compositions within these spaces; however, we also find that contemporary racialized/classed isolation would have been even higher among Grade D tracts if not for prior urban renewal projects [Figure 3; Panel 3].

The final panel of Figure 3 demonstrates how these historical trajectories of inequity underpin contemporary disparities in period life expectancy between Grade A and Grade D tracts. The relatively large PIEs associated with housing values and racialized/classed isolation suggest that these mediators played substantial roles in connecting past redlining grades to contemporary life expectancy with spatially marked tracts. For instance, the PIE associated with housing values $(-1.26 ;-1.54$ to -1.06$)$ suggests that a measurable portion of the 5.95-year life expectancy advantage experienced by Grade A tracts is accounted for by inflated housing values with these neighborhoods; this suggest that redlining played a measurable role in distributing property values across Grade A and Grade D tracts and that this differential distribution of value fed into life expectancy disparities across said places. The PIE associated with racial/classed isolation ($2.47 ;-2.82$ to -2.08 ) reveals a similar story: a considerable portion of the contemporary life expectancy advantage experienced by Grade A tracts vanishes when breaking the link between past redlining and the distribution of more proximal racialized economic isolation. Results also suggest minor PAI effects of both housing values and racialized/classed isolation. These estimands suggest that redlining not only served to segment life expectancy across Grade A and $\mathrm{D}$ tracts by shaping the compositional characteristics of these spaces, but also by influencing these factors' relationships to life expectancy.

As a final insight from this analysis, the CDE displayed in Figure 3, Panel 4 indicates that even after accounting for our mediators, Grade A tracts still experience longer overall life expectancy than their Grade D counterparts. Put differently, the CDE tells us that, while partially explained by observed historical mediators, some portion of the life expectancy advantage experienced by Grade A tracts is underpinned by additional forces of spatial marking operating outside of our measured historical factors.

Turning to our analysis from a structural perspective (R2), Figure 4 below displays a similar mediation analysis, tracing the nearly 10-year difference in 2018 life expectancy between 
concentrated Black working-class communities and concentrated white-professional class communities backwards, along our measured historical mediators, to redlining grades.

[Figure 4]

The last panel of Figure 4 demonstrates that the disparity in life expectancy observed between Black working-class tracts and white professional-class tracts is most heavily underpinned by differences in how property values are distributed across these neighborhoods (PIE housing values $=-2.68 ;-2.96$ to -2.40$)$. Indeed, while other measured historical factors do appear to exert some marginal influence here-including some small contribution stemming from differences in how these communities were marked by HOLC in the 1930s (PIE HOLC grades $=-0.28 ;-0.35$ to -0.21) — more contemporary inequities in how property values were constructed across racialized communities appear to play a much larger role in explaining life expectancy disparities.

Working backwards, Figure 4 also demonstrates that, while Black working-class tracts systematically experience much lower housing valuations than white professional-class tracts, virtually none of this disparity is predicted by former redlining grades or other measured mediators. In Panel 3, we observe that both the PIE (-0.06; -0.08 to -0.05) and the PAI (-0.03; 0.07 to 0.02 ) associated with redlining grades are near zero, which suggest that the explicit assignment of HOLC grades to tracts in the past played only a limited role in constructing more contemporary property values across racialized communities. Following these neighborhoods back even further along our historical mediators, we see that past school segregation and investment into urban renewal projects were influenced by HOLC grades, but that these factors only played a marginal role in explaining life expectancy or housing value disparities that emerged across Black working-class and white-professional class disparities.

Taken altogether, results from our structural analysis suggest that redlining grades only predicted a small portion of the total disparity in 2018 life expectancy observed between Black workingclass tracts and white professional-class tracts. Whether by exerting a direct effect or by becoming embedded in structures distributing more proximal social determinants of health (e.g., systems shaping the distribution of housing values across communities), redlining grades appeared to offer only a very marginal predictive account for the stark life expectancy disparities that emerged between contemporary Black working-class and white professional-class tracts.

\section{DISCUSSION}

In this study, we contribute to the literature on if and how historical redlining connects to contemporary population health through two distinct analyses of HOLC maps as a dynamic social intervention, each of which is motivated by a distinct theoretical starting point. First, using a spatial marking perspective, our results highlight the legacy of tract-level redlining via both observed mediators and unobserved pathways. Tracing these legacies sheds light on how HOLC grades are historically embedded in the distribution of place-based exposure to urban renewal, 
school segregation, property values, raced/classed segregation - and ultimately, risk of mortality. Our results demonstrate that the life expectancy advantage experienced by residents of Grade A tracks relative to residents of Grade D tracts is largely underpinned by the differential distribution of home values and race/class concentrations among these geographies. Redlining does appear to exert some influence on spatialized disparities in life expectancy that is not captured in these observed pathways; yet results suggest that HOLC mapping largely arrived on contemporary, place-based vulnerabilities to premature death by triggering historical trajectories that conditioned more proximal inequities in segregation and property valuation. Further, we find some evidence that redlining became embedded in not only the distribution of these subsequent mediating systems, but also in the relationships of those systems to mortality; for example, elevated racialized economic isolation is more negatively associated with life expectancy in D tracts compared to A tracts. These findings demonstrate that redlining was not a static historical exposure experienced by particular neighborhoods, but continues to be embedded in the distributions and influences of more proximal drivers of population health today.

Second, using a structural perspective, our results highlight that the one-to-one legacies of tractlevel HOLC grades were only one part of a larger project of (re)producing racialized geographies of premature death in the U.S. Indeed, we find that contemporary race-class concentration is strongly linked to housing valuation, and both are in turn strongly linked to life expectancy-but that only a very small proportion of these total disparities are mediated by the fact that some tracts were graded as " $\mathrm{D}$ " by HOLC. This finding is supported in other work which contends that the "effect of redlining" cannot be operationalized through simple one-to-one matching of historical and contemporary Census tract areas (Fields and Raymond 2021; Howell and KorverGlenn 2018). Rather, our findings show that tract-level HOLC grades in the 1930s were only one manifestation of racism as "the state-sanctioned or extralegal production and exploitation of group-differentiated vulnerability to premature death" (Gilmore 2007) — and these logics of structural violence likely informed the organization of housing, labor markets, and healthcare across all neighborhoods in the following decades, not only those that were formally redlined in the 1930s (Dantzler 2021; Faber 2020). Indeed, consider maps of redlining, home valuation, and life expectancy in Cleveland and Houston (Figure 5). Cleveland aligns very closely with the spatial marking perspective, where contemporary low home valuation and low life expectancy are almost perfectly distributed along D grades. In contrast, Houston does not follow this pattern at all, and yet it is very likely that the Houston housing market grew out of the same racist logic of redlining to produce equally large (or larger) racialized disparities in home valuation and life expectancy. As we discuss below, this phenomenon is difficult to isolate in quantitative models and highlights the importance of social theory and triangulation across multiple methods (Du Bois 1898; Itzigsohn and Brown 2020).

When taken together, our results demonstrate a varied and multifaceted legacy of HOLC maps: spatially-marked neighborhoods did experience differential historical trajectories that ultimately shaped life-expectancy within those places, and yet, these neighborhood-based histories that 
were propelled forward by explicit HOLC mapping offer little explanation for how stark health disparities arose across contemporary Black and white neighborhoods at the extremes of racialized and classed isolation. Operationalizing and measuring the "effect of redlining" is dependent on the theoretical starting points used to conceptualize the lasting impacts of this historical intervention.

[Figure 5 here]

\section{Counterfactual considerations}

A counterfactual consideration for historical trajectories that we do not address in the present study is the multilevel nature of these social processes. In operationalizing "redlining" as a placespecific historical exposure, we define the unit of analysis ("place") to be Census tracts, but effects are likely to exist at multiple contextual levels - and importantly, are likely to interact with one another over time and across networks.

As an example of this, consider that there are city-level effects of redlining, such that metropolitan areas that did engage in HOLC mapping in the 1930s became more heavily invested in a "segregationist logic" that accelerated a broader project of institutionally investing in spatial, racialized delineation. ${ }^{28}$ These processes, which may generate variation between cities that were and were not redlined, may sit alongside distinct tract-level effects, which stem from a neighborhood within a redlined city being marked as "Grade A" instead of "Grade D."

In face of potentially co-occurring effects like these, we note two counterfactual considerations: 1) concerns related to positivity, depending on the number of levels in play, and 2) concerns related to interference. In our example, perhaps we could incorporate city-level effects as well as tract-level effects in a hierarchical mediation analysis, but these effects are co-constituted over time (Oakes 2009; Sharkey and Elwert 2011; Wodtke, Harding, and Elwert 2011) and we have to consider the fact that, on an even broader, national level, one might argue that all neighborhoods are "exposed" to a historical trajectory that included massive federal investment in institutionalizing the notion that financial risk is tied to racial composition. Both of these issues imply complicated counterfactuals that are theoretically meaningful: Were tract-level trajectories affected by city-level redlining, even if the tract itself was not redlined? Were tract-level trajectories influenced by the redlining history of adjacent tracts? What if the United States had not invested in the project of redlining whatsoever?

Still, despite the importance of these alternative counterfactual frames, development of observational causal inference methods in population health has largely been driven by evaluating clinical treatments rather than examining complex, multilevel social processes (Robinson and Bailey 2020) - and these methods include "system-preserving" assumptions in a way that is likely inconsistent with the intricate social processes being studied (Jackson and Arah 2020; Diez Roux 2011). As discussed here, quantitative counterfactual inference can be a 
powerful tool for population health scientists to be explicit about assumptions and theory related to specific estimands, especially around confounding and mediation (Lundberg, Johnson, and Stewart 2021; Robinson and Bailey 2020; Schwartz, Gatto, and Campbell 2017). But we also quickly run up against the theoretical bounds of quantitative methods (Du Bois 1898; Itzigsohn and Brown 2020), highlighting the need for deeper engagement with other empirical methods such as reflexive qualitative inquiry (Ford and Airhihenbuwa 2010), descriptions of historical context (Chowkwanyun 2011; Williams 2019), and further engagement with critical, intersectional, feminist, and postcolonial theories to best understand the long-run effects of broad, dynamic historical exposures (Delgado and Stefancic 2017; Crenshaw 2017; Glenn 2015).

\section{Limitations}

Our analysis has several limitations. As a general consideration, it is difficult for quantitative analyses of processes that unfolded over the course of decades to meet the conditions necessary for identifying unbiased "causal" estimates. One major limiting factor is the depth and availability of historical data that might be used to satisfy assumptions pertaining to unconfoundedness. Indeed, while innovative data curation efforts (Bailey and Tolnay 2015; Cunningham, Lee, and Ward 2021; Nelson et al. n.d.; Ruggles et al. 2021; Ward n.d.) have provided researchers with some capacity to reconstruct the social conditions that shaped the distribution of both historical treatments and subsequent outcomes, the absence of widespread, formalized data collection mechanisms during the historical periods typically being studied means that researchers are limited in their ability to condition estimates on pretreatment information - and bolster confidence that results are not driven by unobserved confounders. By the same means, we often lack precise historical information on alternative mechanisms that might unfold concurrently, over history, alongside the mechanisms that we can observe (posttreatment confounding); lacking this detailed intermediate information similarly complicates the causal interpretation of our mediation estimands.

Still, despite these concerns around causality stemming from limited historical data, we contend that there is much to be gained from studying the long-run effects of historical exposures within a counterfactual mediation framework. Research questions that ask how much of the association between exposure $X$ and outcome $Y$ is explained by some intermediate variable $M$ invoke counterfactual comparisons. Empirical frameworks like the one we utilize here make these counterfactual contrasts explicit and connect our research questions to empirical estimands that help us evaluate our theoretical ideas. Moreover, an approach like the parametric g-formula avoids the pitfalls of alternative, commonly used approaches to unpacking historical processes (e.g., Baron-Kenny mediation) that are also predicated on counterfactual logic, but risk inducing substantial bias and obscuring the intended conceptual interpretation of the quantities that researchers aim to produce in testing their critical hypotheses (Lundberg et al. 2021). Altogether, while it cannot ensure fully unbiased casual estimates due to limitations of historical data, our counterfactual approach does allow us to provide a careful, nuanced, and conceptually grounded 
description of a long-run historical process and avoid sources of error that we do have control over (e.g., the handling of observed post-treatment relations).

As a related consideration, we call attention to contemporary data collection efforts. Current structural phenomena with the same embedded logic of redlining in conflating "race" with "risk" -- such as the increased participation of private equity in the delivery of healthcare and housing, credit and loan algorithms, and evolving technologies of algorithmic surveillance and policing -will continue to set the stage for subsequent forms of institutionalized violence that ultimately produce population health inequities. To ensure that researchers are able to carefully trace the consequences of current socio-structural arrangements and institutional exposures for future populations, we must make a concentrated effort to better monitor and collect detailed data on these systems themselves. As noted elsewhere (Ford and Airhihenbuwa 2010; Reskin 2012; Robinson and Bailey 2020; Williams 2019), we must shift contemporary data collection to heavily monitor relational systems (e.g., banks; landlords; real estate interests; law enforcement; private equity) - rather than only surveying individuals and households - to ensure that researchers have the materials needed to satisfy assumptions pertaining to causal explanation and produce careful descriptions of the long-run effects of past institutional and structural exposures.

One final limitation concerns inferences based on predicting modeled, tract-level period life expectancy, which may result in conclusions that are partially based on the covariance between our exposures/mediators and measures used in that model. See Appendix for a discussion of the NVSS life expectancy estimates and a robustness check that confirms that our results hold under different assumptions concerning these data.

\section{Policy implications}

Racism has historically used the racialization of people and place to arrange violence via redlining, urban renewal, policing, and other instruments of dispossession and displacement that are necessary to maximize place-based capital accumulation (Sewell 2016; Sugrue 1997; Taylor 2019;). This has durable effects in distributing place-based risks and privileges, but also in constructing their relation to premature mortality (Bailey, Feldman, and Bassett 2021; Purifoy and Seamster 2021; Tilly 1999). Still, formal redlining was only one manifestation of the broader project of racist abstraction via the financialization of housing that increasingly shapes both antiBlack dispossession (e.g., ownership, property valuation, ability to build equity) and displacement (e.g., evictions, foreclosures) (Dantzler 2021; Fields and Raymond 2021). As demonstrated by the history of redlining in American housing, it is critical to center the pervasive and insidious roles of public-private partnerships in organizing racialized displacement and dispossession for the sake of capital accumulation (Faber 2021; Taylor 2019). While redlining and urban renewal might be seen as blunt forms of violence, these logics and partnerships have informed the evolution of more indirect, abstracted instruments of racial violence that drive place-based differentiation today, including the financialization of housing and healthcare, credit 
and loan algorithms, and more (Dantzler 2021; Fields and Raymond 2021; Rugh and Massey 2010; Robinson 2020).

Centering the practice of redlining within the long history of public-private projects of racist exclusion and predatory inclusion (Pulido 2017; Taylor 2019), our findings can be contextualized within a more general tension between two place-based policy frameworks: (1) the equity-informed targeting of resources to "vulnerable" communities and (2) engagement with movements aimed at dismantling larger sociopolitical racist projects maintained within capitalist, white supremacist institutions. While important from a restorative justice standpoint, the first framework risks legitimizing current neoliberal combinations of technocratic, piecemeal policyinitiatives to address structural problems (Schwartz, Gatto, and Campbell 2016). While such place-based policies can be made historically contingent, there is a circular logic to leveraging place-based indices (e.g., the CDC Social Vulnerability Index) to understand what makes certain communities "vulnerable"-communities are vulnerable because they have the traits of vulnerability, such as low median income. Our findings demonstrate that simply targeting "D" neighborhoods in such frameworks has limited potential for achieving racial equity in health (Creary 2021).

In contrast, a relational framework asserts that the racist contours of place-based risk do not exist in a vacuum, but rather are an evolving, adaptive precondition for the extraction and dispossession necessary for accumulating privilege in other communities (Cummins et al. 2007; Dantzler 2021; Fields and Raymond 2021; Purifoy and Seamster 2021). There is a certain churning of people through space that is necessary for maximizing place-based returns on capital investment, ${ }^{20}$ highlighting the fact that histories of place are not deterministic: as seen in our results, $70 \%$ of hyper-segregated, working-class Black neighborhoods today are located in areas never graded as D (see Figure 5). The financialization of real estate on a global scale has vastly accelerated these racist, place-based cycles of dispossession and displacement for the sake of speculative profiteering: for example, private equity firms increasingly investing in rental property in low-income neighborhoods and evicting at higher rates (Fields, n.d.), and the securitization of debt and targeting of subprime lending products in Black neighborhoods organizing the fallout of the Great Recession (Rugh and Massey 2010). In parallel, speculative private equity creeps further into healthcare delivery; for example, private equity ownership in safety-net hospitals serving historically Black neighborhoods leads to increased instability in access and worse patient outcomes (Williams and Collins 2001). Health policy must consider its role within this broader political economy, the racial contours of which are predicated on the conflation of "financial risk" with "race" formalized, in part, by the segregationist logics of redlining and deeply embedded in the subsequent delivery systems of education, housing, and healthcare. The long reach of this history is seen in the racialized geographic relations of all American cities and communities, not just those that were explicitly graded as "undesirable" in the 1930s. 


\section{Conclusions}

In order to break systematic arrangements that reproduce place-based racial inequality over time, we echo calls from others that social and health policy must engage with theories of racism as a fundamental cause of population health (Bailey, Feldman, and Bassett 2021; Laster Pirtle 2020;

Phelan and Link 2015; Williams and Collins 2001). A technocratic social science can incorporate redlining maps as a marginal risk factor in documenting contemporary racial disparities and targeting piecemeal interventions; an emancipatory research and policy agenda can engage with the historical role of redlining in the broader political economy of place, including the fact that historical redlining grades are no longer a necessary instrument for maintaining the larger racist project of conflating "race" and "risk" (Bailey, Feldman, and Bassett 2021; Benjamin 2019; Ford and Airhihenbuwa 2010).

\section{References}

Bailey, Amy Kate, and Stewart Tolnay. 2015. Lynched: The Victims of Southern Mob Violence. University of North Carolina Press.

Bailey, Zinzi D., Justin M. Feldman, and Mary T. Bassett. 2021. "How Structural Racism Works - Racist Policies as a Root Cause of U.S. Racial Health Inequities." New England Journal of Medicine 384 (8): 768-73. https://doi.org/10.1056/NEJMms2025396.

Benjamin, Ruha. 2019. Race after Technology: Abolitionist Tools for the New Jim Code. Polity. Buuren, Stef van, and Karin Groothuis-Oudshoorn. 2011. "Mice: Multivariate Imputation by Chained Equations in R.” Journal of Statistical Software 45 (3): 1-67. https://doi.org/10.18637/jss.v045.i03.

Chowkwanyun, Merlin. 2011. "The Strange Disappearance of History from Racial Health Disparities Research.” Du Bois Review: Social Science Research on Race 8 (1): 253-70. Creary, Melissa S. 2021. "Bounded Justice and the Limits of Health Equity." Journal of Law, Medicine \& Ethics 49 (2): 241-56. https://doi.org/10.1017/jme.2021.34.

Crenshaw, Kimberlé, ,. 2017. On Intersectionality : Essential Writings.

Cummins, Steven, Sarah Curtis, Ana V. Diez-Roux, and Sally Macintyre. 2007. "Understanding and Representing 'Place' in Health Research: A Relational Approach." Placing Health in Context 65 (9): 1825-38. https://doi.org/10.1016/j.socscimed.2007.05.036.

Cunningham, David, Hedwig Lee, and Geoff Ward. 2021. "Legacies of Racial Violence: Clarifying and Addressing the Presence of the Past." The ANNALS of the American Academy of Political and Social Science 694 (1): 8-20.

Daniel, R. M., B. L. De Stavola, S. N. Cousens, and S. Vansteelandt. 2015. "Causal Mediation Analysis with Multiple Mediators." Biometrics 71 (1): 1-14. https://doi.org/10.1111/biom.12248.

Dantzler, Prentiss A. 2021. "The Urban Process under Racial Capitalism: Race, Anti-Blackness, and Capital Accumulation." Journal of Race, Ethnicity and the City 0 (0): 1-22. https://doi.org/10.1080/26884674.2021.1934201.

Delgado, Richard, and Jean Stefancic. 2017. Critical Race Theory (Third Edition): An Introduction. New York University Press. https://doi.org/10.18574/9781479851393. 
Diez Roux, Ana V. 2011. "Complex Systems Thinking and Current Impasses in Health Disparities Research.” American Journal of Public Health 101 (9): 1627-34. https://doi.org/10.2105/AJPH.2011.300149.

Du Bois, W. E. B. 1898. "The Study of the Negro Problems." The Annals of the American Academy of Political and Social Science 11: 1-23.

Faber, Jacob. 2021. "Contemporary Echoes of Segregationist Policy: Spatial Marking and the Persistence of Inequality." Urban Studies 58 (5): 1067-86. https://doi.org/10.1177/0042098020947341.

- 2020. "We Built This: Consequences of New Deal Era Intervention in America's Racial Geography." American Sociological Review 85 (5): 739-75. https://doi.org/10.1177/0003122420948464.

Fields, Desiree. n.d. "The Rise of the Corporate Landlord: The Institutionalization of the SingleFamily Rental Market and Potential Impacts on Renters.” Right to the City Alliance. http://homesforall.org/wp-content/uploads/2014/07/corp-landlord-report-web.pdf.

Fields, Desiree, and Elora Lee Raymond. 2021. "Racialized Geographies of Housing Financialization.” Progress in Human Geography, April, 03091325211009299. https://doi.org/10.1177/03091325211009299.

Ford, Chandra L., and Collins O. Airhihenbuwa. 2010. "The Public Health Critical Race Methodology: Praxis for Antiracism Research.” Social Science \& Medicine 71 (8): 139098. https://doi.org/10.1016/j.socscimed.2010.07.030.

Gelman, Andrew, and Guido Imbens. 2013. "Why Ask Why? Forward Causal Inference and Reverse Causal Questions.” 19614. NBER Working Papers. National Bureau of Economic Research, Inc. https://www.nber.org/papers/w19614.

Gilmore, Ruth Wilson. 2007. Golden Gulag. 1st ed. University of California Press.

Glenn, Evelyn Nakano. 2015. "Settler Colonialism as Structure: A Framework for Comparative Studies of U.S. Race and Gender Formation." Sociology of Race and Ethnicity 1 (1): 5272. https://doi.org/10.1177/2332649214560440.

Howell, Junia, and Elizabeth Korver-Glenn. 2018. "Neighborhoods, Race, and the Twenty-FirstCentury Housing Appraisal Industry." Sociology of Race and Ethnicity 4 (4): 473-90. https://doi.org/10.1177/2332649218755178.

- 2020. "The Increasing Effect of Neighborhood Racial Composition on Housing Values, 1980-2015.” Social Problems, no. spaa033 (September). https://doi.org/10.1093/socpro/spaa033.

Itzigsohn, Jose, and Karida Brown. 2020. The Sociology of W. E. B. Du Bois: Racialized Modernity and the Global Color Line. NYU Press.

Jackson, John W, and Onyebuchi A Arah. 2020. "Invited Commentary: Making Causal Inference More Social and (Social) Epidemiology More Causal.” American Journal of Epidemiology 189 (3): 179-82. https://doi.org/10.1093/aje/kwz199.

Jackson, John W, and Tyler J VanderWeele. 2019. "Intersectional Decomposition Analysis with Differential Exposure, Effects, and Construct.” Social Science \& Medicine (1982) 226 (April): 254-59. https://doi.org/10.1016/j.socscimed.2019.01.033.

Keil, Alexander P, Jessie K Edwards, David B Richardson, Ashley I Naimi, and Stephen R Cole. 2014. "The Parametric G-Formula for Time-to-Event Data: Intuition and a Worked Example." Epidemiology (Cambridge, Mass.) 25 (6): 889-97. https://doi.org/10.1097/EDE.0000000000000160. 
Kohler-Hausmann, Issa. 2019. "Eddie Murphy and the Dangers of Counterfactual Causal Thinking About Detecting Racial Discrimination." Nw. UL Rev, no. 113.

Krieger, Nancy, Emily Wright, Jarvis T Chen, Pamela D Waterman, Eric R Huntley, and Mariana Arcaya. 2020a. "Cancer Stage at Diagnosis, Historical Redlining, and Current Neighborhood Characteristics: Breast, Cervical, Lung, and Colorectal Cancers, Massachusetts, 2001-2015.” American Journal of Epidemiology 189 (10): 1065-75. https://doi.org/10.1093/aje/kwaa045.

Krieger, Nancy, Gretchen Van Wye, Mary Huynh, Pamela D. Waterman, Gil Maduro, Wenhui Li, R. Charon Gwynn, Oxiris Barbot, and Mary T. Bassett. 2020b. "Structural Racism, Historical Redlining, and Risk of Preterm Birth in New York City, 2013-2017." American Journal of Public Health 110 (7): 1046-53. https://doi.org/10.2105/AJPH.2020.305656.

Krysan, Maria, and Kyle Crowder. 2017. Cycle of Segregation. Russell Sage Foundation. https://doi.org/10.7758/9781610448697.

Laster Pirtle, Whitney N. 2020. "Racial Capitalism: A Fundamental Cause of Novel Coronavirus (COVID-19) Pandemic Inequities in the United States." Health Education \& Behavior 47 (4): 504-8. https://doi.org/10.1177/1090198120922942.

Logan, John, and Harvey Luskin Molotch. 1987. The Political Economy of Place. University of California Press.

Lundberg, Ian, Rebecca Johnson, and Brandon M. Stewart. 2021. "What Is Your Estimand? Defining the Target Quantity Connects Statistical Evidence to Theory." American Sociological Review 86 (3): 532-65. https://doi.org/10.1177/00031224211004187.

Lynch, Emily, Lorraine Halinka Malcoe, Sarah Laurent, Jason Richardson, Bruce Mitchell, and Helen C.S. Meier. 2021. "The legacy of structural racism: Associations between historic redlining, current mortgage lending, and health." SSM - Population Health 14.

McClure, Elizabeth, Lydia Feinstein, Evette Cordoba, Christian Douglas, Michael Emch, Whitney Robinson, Sandro Galea, and Allison E. Aiello. 2019. "The Legacy of Redlining in the Effect of Foreclosures on Detroit Residents' Self-Rated Health." Health \& Place 55 (January): 9-19. https://doi.org/10.1016/j.healthplace.2018.10.004.

McClure, Elizabeth S, Pavithra Vasudevan, Zinzi Bailey, Snehal Patel, and Whitney R Robinson. 2020. "Racial Capitalism Within Public Health-How Occupational Settings Drive COVID-19 Disparities.” American Journal of Epidemiology 189 (11): 1244-53. https://doi.org/10.1093/aje/kwaa126.

Naimi, Ashley I, Mireille E Schnitzer, Erica E M Moodie, and Lisa M Bodnar. 2016. "Mediation Analysis for Health Disparities Research.” American Journal of Epidemiology 184 (4): 315-24. https://doi.org/10.1093/aje/kwv329.

Nardone, Anthony, Joan A Casey, Rachel Morello-Frosch, Mahasin Mujahid, John R Balmes, and Neeta Thakur. 2020. "Associations between Historical Residential Redlining and Current Age-Adjusted Rates of Emergency Department Visits Due to Asthma across Eight Cities in California: An Ecological Study." The Lancet Planetary Health 4 (1): e24-31. https://doi.org/10.1016/S2542-5196(19)30241-4.

National Center for Health Statistics. 2018. "U.S. Small-Area Life Expectancy Estimates Project (USALEEP).” https://www.cdc.gov/nchs/nvss/usaleep/usaleep.html

Nelson, Robert, LaDale Winling, Richard Marciano, and Nathan Connolly. n.d. "Mapping Inequality." Mapping Inequality. Accessed July 22, 2021. https://dsl.richmond.edu/panorama/redlining/. 
Nelson, Robert, and Ayers, Edward. n.d. "Renewing Inequality: Family Displacements through Urban Renewal, 1950-1966." Accessed July 22, 2021. https://dsl.richmond.edu/panorama/renewal/\#view=0/0/1\&viz=cartogram

Oakes, J Michael. 2009. "Commentary: Individual, Ecological and Multilevel Fallacies." International Journal of Epidemiology 38 (2): 361-68. https://doi.org/10.1093/ije/dyn356.

Phelan, Jo C., and Bruce G. Link. 2015. "Is Racism a Fundamental Cause of Inequalities in Health?” Annual Review of Sociology 41 (1): 311-30. https://doi.org/10.1146/annurevsoc-073014-112305.

Pulido, Laura. 2017. “Geographies of Race and Ethnicity II: Environmental Racism, Racial Capitalism and State-Sanctioned Violence." Progress in Human Geography 41 (4): 524 33. https://doi.org/10.1177/0309132516646495.

Purifoy, Danielle M, and Louise Seamster. 2021. "Creative Extraction: Black Towns in White Space.” Environment and Planning D: Society and Space 39 (1): 47-66. https://doi.org/10.1177/0263775820968563.

Radford, Gail. 1996. Modern Housing for America: Policy Struggles in the New Deal Era. University of Chicago Press.

Reskin, Barbara. 2012. "The Race Discrimination System.” Annual Review of Sociology 38 (1): 17-35. https://doi.org/10.1146/annurev-soc-071811-145508.

Richardson, Jason, Bruce Mitchell, Helen Meier, Emily Lynch, and Jad Edlebi. 2020. "Redlining and Neighborhood Health." National Community Reinvestment Coalition. https://ncrc.org/holc-health/.

Robins, James. 1986. “A New Approach to Causal Inference in Mortality Studies with a Sustained Exposure Period-Application to Control of the Healthy Worker Survivor Effect." Mathematical Modelling 7 (9): 1393-1512. https://doi.org/10.1016/02700255(86)90088-6.

Robins, James M., Miguel Ángel Hernán, and Babette Brumback. 2000. "Marginal Structural Models and Causal Inference in Epidemiology." Epidemiology 11 (5).

Robinson, John N, III. 2020. "Making Markets on the Margins: Housing Finance Agencies and the Racial Politics of Credit Expansion.” American Journal of Sociology 125 (4): 9741029. https://doi.org/10.1086/707927.

Robinson, John N, III. 2021. 'Surviving Capitalism: Affordability as a Racial 'Wage' in Contemporary Housing Markets.” Social Problems 68 (2): 321-39. https://doi.org/10.1093/socpro/spaa078.

Robinson, Whitney R, and Zinzi D Bailey. 2020. "Invited Commentary: What Social Epidemiology Brings to the Table - Reconciling Social Epidemiology and Causal Inference." American Journal of Epidemiology 189 (3): 171-74. https://doi.org/10.1093/aje/kwz197.

Rothstein, Richard. 2017. The Color of Law: A Forgotten History of How Our Government Segregated America. New York: Liveright.

Ruggles, Steven, Sarah Flood, Sophia Foster, Ronald Goeken, Jose Pacas, Megan Schouweiler, and Matthew Sobek. 2021. "IPUMS USA: Version 11.0.” Minneapolis, MN: IPUMS. https://doi.org/10.18128/D010.V11.0.

Rugh, Jacob S., and Douglas S. Massey. 2010. "Racial Segregation and the American Foreclosure Crisis." American Sociological Review 75 (5): 629-51. https://doi.org/10.1177/0003122410380868. 
Schwartz, Sharon, Nicolle M. Gatto, and Ulka B. Campbell. 2016. "Causal Identification: A Charge of Epidemiology in Danger of Marginalization." Annals of Epidemiology 26 (10): 669-73. https://doi.org/10.1016/j.annepidem.2016.03.013. . 2017. "Heeding the Call for Less Casual Causal Inferences: The Utility of Realized (Quantitative) Causal Effects." Annals of Epidemiology 27 (6): 402-5. https://doi.org/10.1016/j.annepidem.2017.05.012.

Sewell, Abigail A. 2016. "The Racism-Race Reification Process: A Mesolevel Political Economic Framework for Understanding Racial Health Disparities." Sociology of Race and Ethnicity 2 (4): 402-32. https://doi.org/10.1177/2332649215626936.

Sharkey, Patrick. 2013. Stuck in Place: Urban Neighborhoods and the End of Progress toward Racial Equality. The University of Chicago Press.

Sharkey, Patrick, and Felix Elwert. 2011. "The Legacy of Disadvantage: Multigenerational Neighborhood Effects on Cognitive Ability." American Journal of Sociology 116 (6): 1934-81. https://doi.org/10.1086/660009.

Sugrue, Thomas J. 1997. The Origins of the Urban Crisis. Princeton University Press.

Taylor, Keeanga-Yamahtta. 2019. Race for Profit. University of North Carolina Press. http://www.jstor.org/stable/10.5149/9781469653686_taylor.

Tilly, Charles. 1999. Durable Inequality. University of California Press.

U.S. Census Bureau. 2020. "2015-2019 American Community Survey 5-year Sample.” https://www.census.gov/newsroom/press-kits/2020/acs-5-year.html

U.S Department of Education. n.d. "Elementary/Secondary Information System.” Institute of Education Sciences, National Center for Education Statistics. Accessed July 22, 2021. https://nces.ed.gov/ccd/elsi/

VanderWeele, Tyler J. 2009. "Marginal Structural Models for the Estimation of Direct and Indirect Effects." Epidemiology 20 (1). https://journals.lww.com/epidem/Fulltext/2009/01000/Marginal_Structural_Models_for_t he_Estimation_of.6.aspx.

VanderWeele, Tyler J. 2014. "A Unification of Mediation and Interaction: A 4-Way Decomposition.” Epidemiology (Cambridge, Mass.) 25 (5): 749-61. https://doi.org/10.1097/EDE.0000000000000121.

Wang, Aolin, and Onyebuchi A. Arah. 2015. "G-Computation Demonstration in Causal Mediation Analysis." European Journal of Epidemiology 30 (10): 1119-27. https://doi.org/10.1007/s10654-015-0100-z.

Ward, Geoff. n.d. "Racial Violence Archive." Accessed July 22, 2021. https://www.racialviolencearchive.com/.

Williams, D R, and C Collins. 2001. "Racial Residential Segregation: A Fundamental Cause of Racial Disparities in Health." Public Health Reports (Washington, D.C. : 1974) 116 (5): 404-16. https://doi.org/10.1093/phr/116.5.404.

Williams, Deadric T. 2019. "A Call to Focus on Racial Domination and Oppression: A Response to "Racial and Ethnic Inequality in Poverty and Affluence, 1959-2015"." Population Research and Policy Review 38 (5): 655-63.

Wodtke, Geoffrey T., David J. Harding, and Felix Elwert. 2011. "Neighborhood Effects in Temporal Perspective: The Impact of Long-Term Exposure to Concentrated Disadvantage on High School Graduation.” American Sociological Review 76 (5): $713-$ 36. https://doi.org/10.1177/0003122411420816. 
Zaimi, Rea. 2020. "Making Real Estate Markets: The Co-Production of Race and Property Value in Early 20th Century Appraisal Science.” Antipode 52: 1539-1559.

Zillow. 2019. "Zillow Home Value Index Methodology, 2019 Revision." https://www.zillow.com/research/zhvi-methodology-2019-highlights-26221/

Zuberi, Tukufu, and Eduardo Bonilla-Silva. 2008. White Logic, White Methods : Racism and Methodology. Lanham: Rowman \& Littlefield Publishers. 
FIGURE 1. Directed acyclic diagrams (DAGs) tracing connections between tract-level HOLC redlining grades $(1=\mathrm{D}, 0=\mathrm{A})$ in 1935-1940 to subsequent mediators, ending with period life expectancy (LE) in 2018. NOTES: HOLC $=$ Home Owners' Loan Corporation, ICE $=$ index of concentration at the extremes.
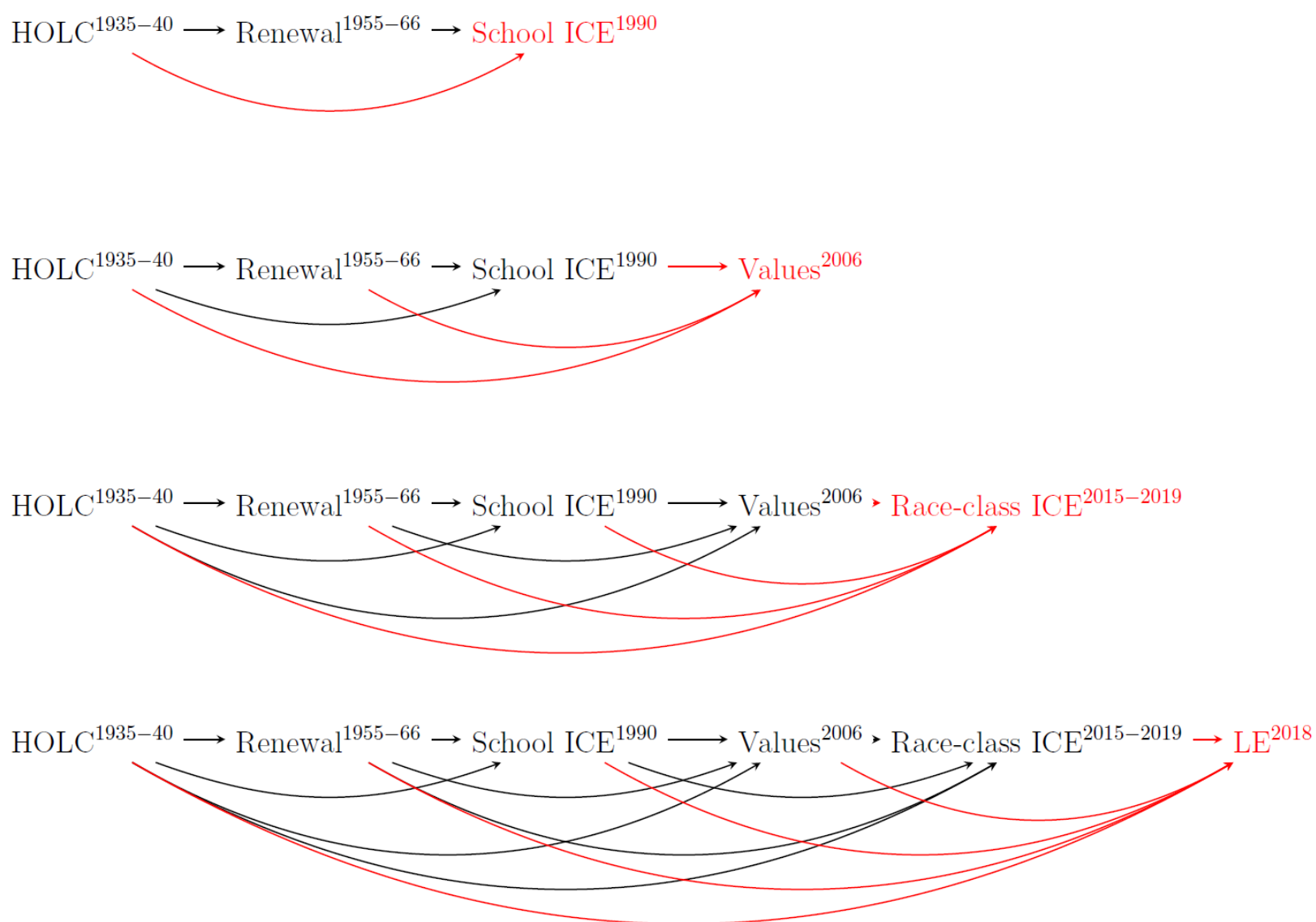
FIGURE 2. Descriptive statistics across four types of tracts: 1) tracts graded as "A", 2) tracts graded as "D", 3) white professional-class tracts (2015-2019 index of concentration at the extremes $<=5$ th percentile), and 4) Black working-class tracts (2015-2019 index of concentration at the extremes $>=95$ th percentile).
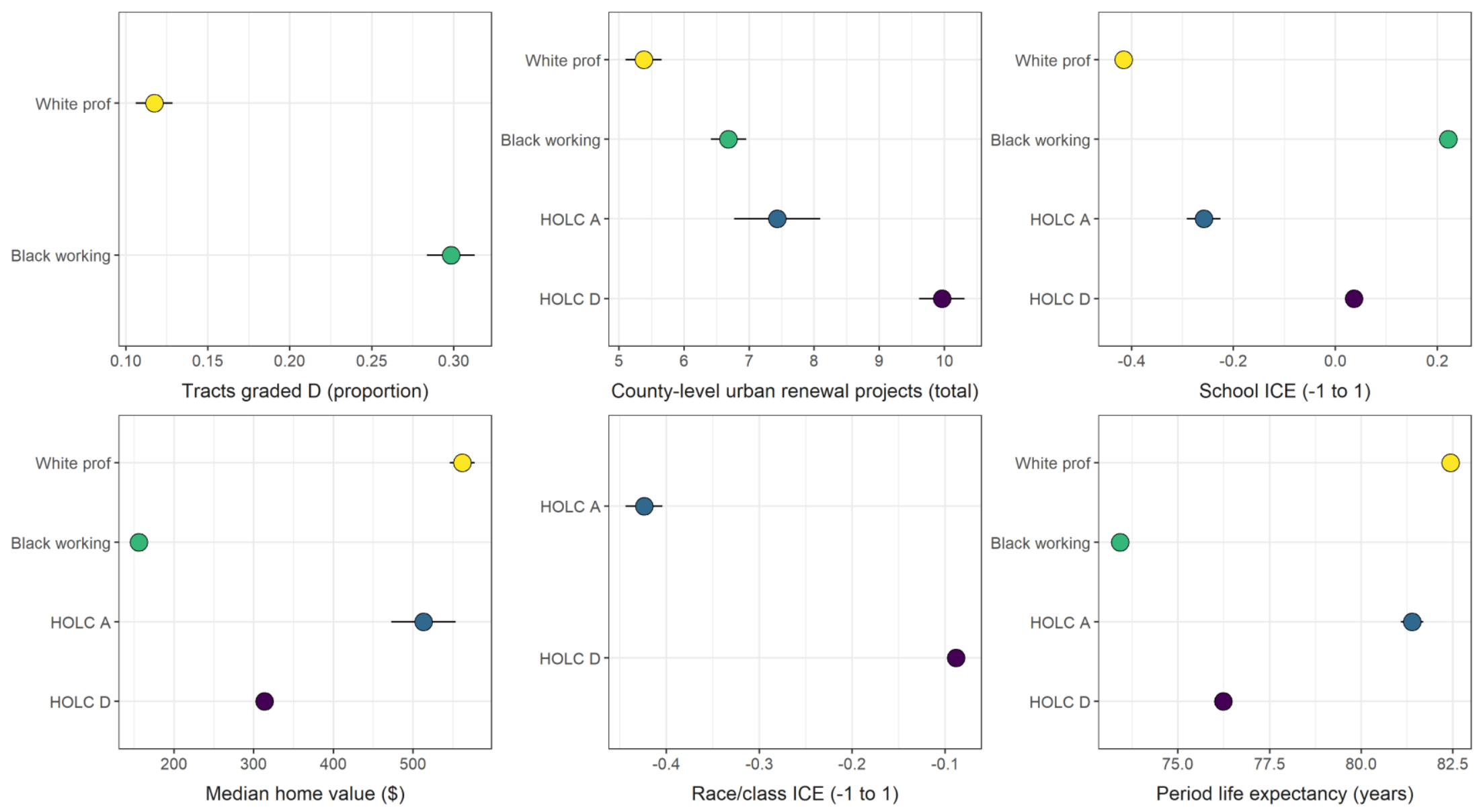
FIGURE 3. Results for mediation analysis R1, examining how the spatial marking of place translates into historical trajectories of school segregation, housing values, and contemporary segregation influencing contemporary period life expectancy in those places (HOLC "D" vs. HOLC “A”). NOTES: HOLC = Home Owners' Loan Corporation, ICE $=$ index of concentration at the extremes, $\mathrm{UR}=$ urban renewal, $\mathrm{CDE}=$ controlled direct effect, $\mathrm{PIE}=$ pure indirect effect, $\mathrm{PAI}=$ proportion attributable to interaction.

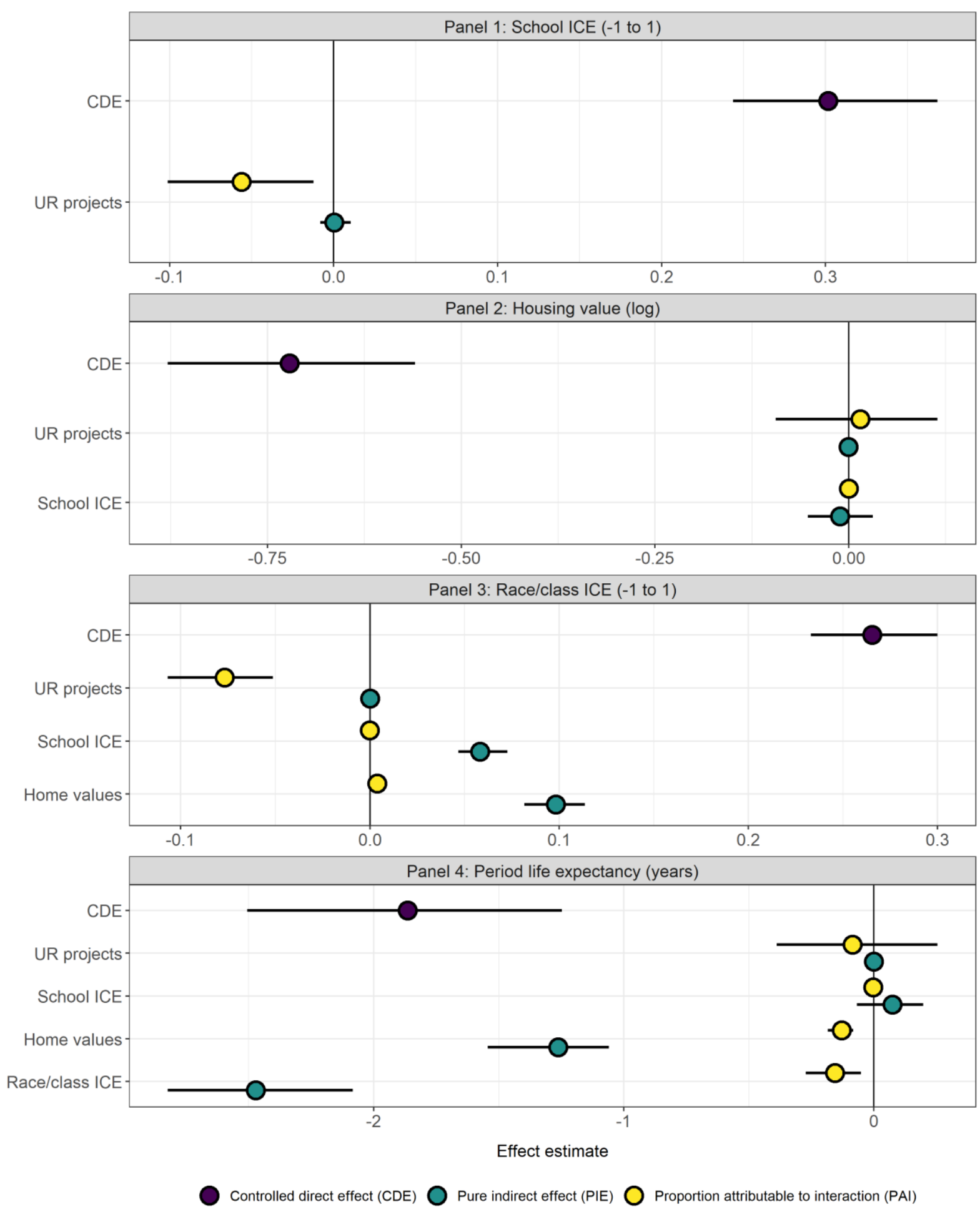


FIGURE 4. Results for mediation analysis R2, examining the extent to which the spatial marking of place predicts the total difference in average life expectancy between 2015-2019 Black working-class vs. white professional-class Census tracts. NOTES: HOLC $=$ Home Owners' Loan Corporation, ICE $=$ index of concentration at the extremes, $\mathrm{UR}=$ urban renewal, $\mathrm{CDE}=$ controlled direct effect, $\mathrm{PIE}=$ pure indirect effect, $\mathrm{PAI}=$ proportion attributable to interaction.
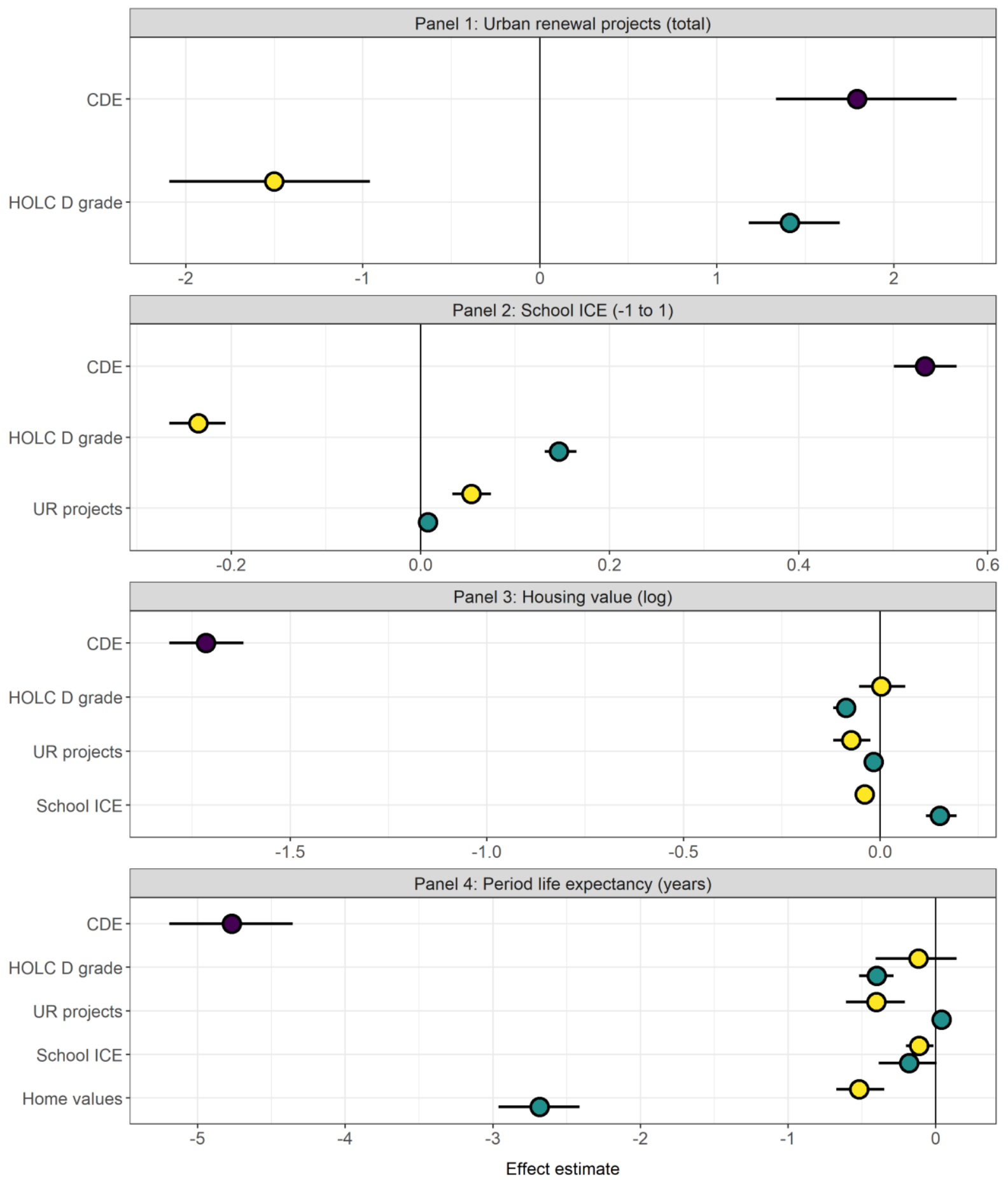

Controlled direct effect (CDE) $\bigcirc$ Pure indirect effect (PIE) $\bigcirc$ Proportion attributable to interaction (PAI) 
FIGURE 5. Maps of D graded tracts (1935-1940), median house values in thousands (2006), and race-class ICE (2015-2019) in two types of cities: 1) overlapping D grades and contemporary race-class ICE (Cleveland, $\mathrm{OH}$ ) and 2) non-overlapping D grades and contemporary race-class ICE (Dallas/Fort Worth, TX). NOTES: HOLC = Home Owners' Loan Corporation, ICE = index of concentration at the extremes.

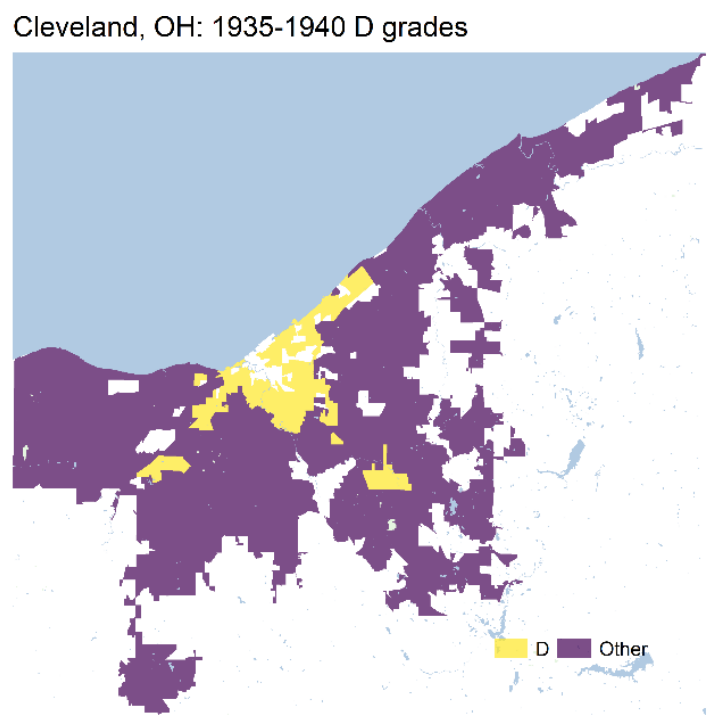

Dallas/Fort Worth, TX: 1935-1940 D grades

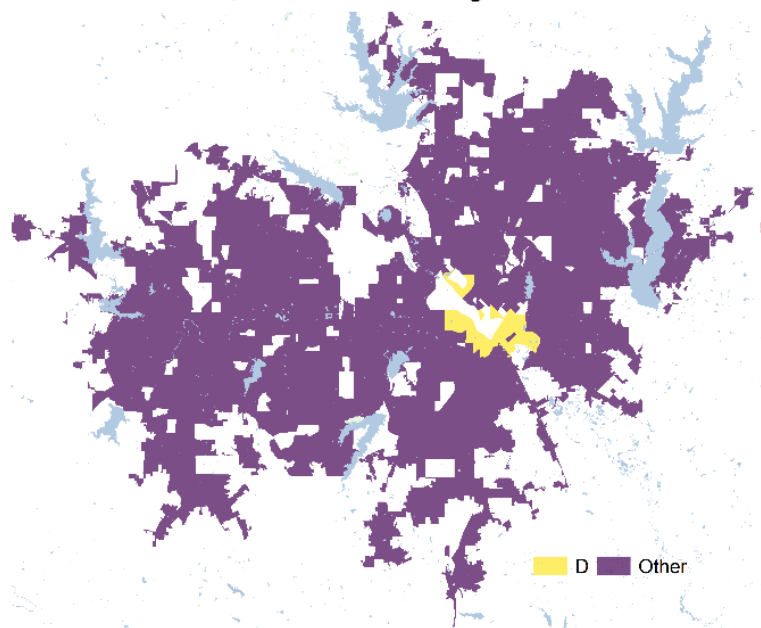

Cleveland, $\mathrm{OH}: 2006$ home value

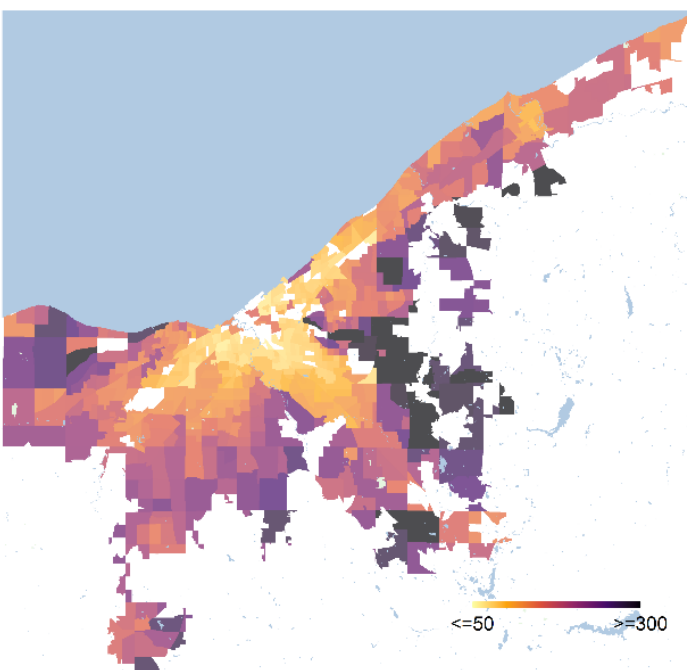

Dallas/Fort Worth, TX: 2006 home value

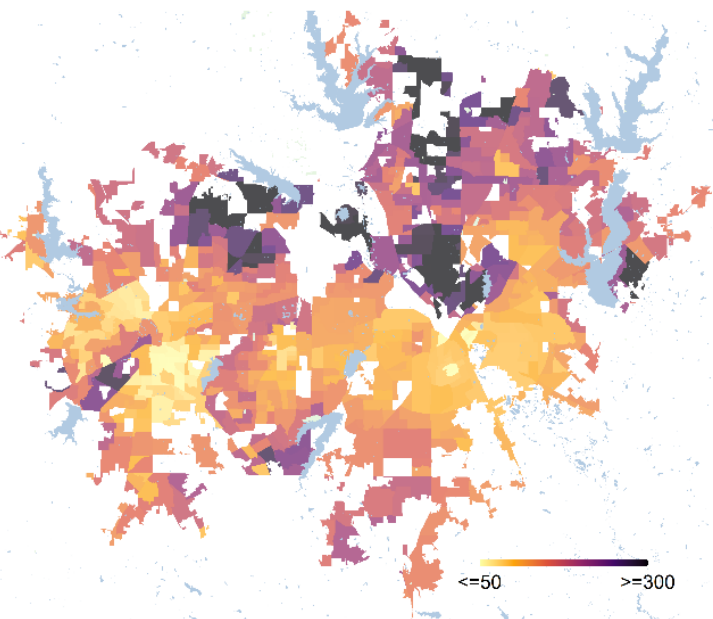

Cleveland, OH: 2015-2019 race/class ICE

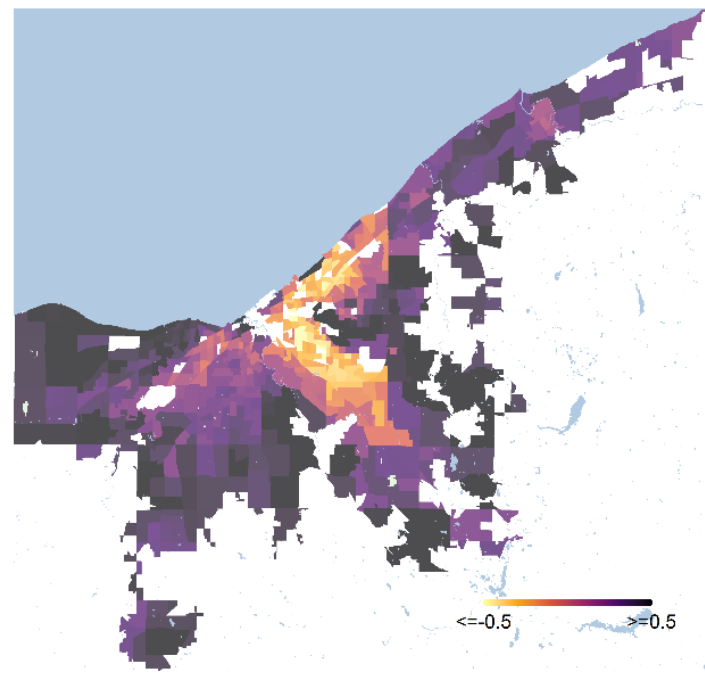

Dallas/Fort Worth, TX: 2015-2019 race/class ICE

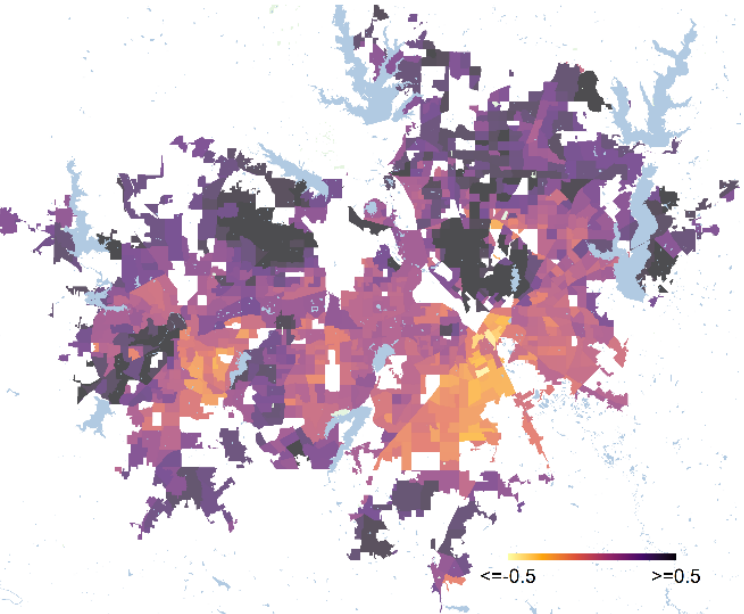




\section{Appendix}

\section{A1. Data Sources}

\begin{tabular}{|c|c|c|c|c|}
\hline Variable & Year & Geography & Source & Notes \\
\hline $\begin{array}{l}\text { Percent Black, percent foreign-born, } \\
\text { unemployment rate, population size, } \\
\text { median home value, and the Black-white } \\
\text { homeownership ratio }\end{array}$ & 1930 & $\begin{array}{l}\text { Counties } \\
\text { (2010 Census, } \\
\text { harmonized) }\end{array}$ & $\begin{array}{l}\text { Decennial Census compiled by } \\
\text { the Integrated Public Use } \\
\text { Microdata Series (IPUMS) } \\
\text { (Ruggles et. al. 2021). }\end{array}$ & $\begin{array}{l}\text { Calculated as the average in the counties } \\
\text { overlapping with each Census tract. }\end{array}$ \\
\hline $\begin{array}{l}\text { Tract-level redlining grades from the } \\
\text { Home Owners' Loan Corporation }\end{array}$ & $1935-1940$ & $\begin{array}{l}\text { Tracts } \\
\text { (2010 Census) }\end{array}$ & $\begin{array}{l}\text { Richmond Mapping Inequality } \\
\text { Nelson et. al. n.d.). }\end{array}$ & $\begin{array}{l}\text { Calculated as any tract }>50 \% \text { A vs. }>50 \% \mathrm{D} \\
\text { (first mediation) and average grade }(\mathrm{D}=4, \ldots \text {, } \\
\mathrm{A}=1 \text {, none }=0 \text { ) weighted by geographic overlap } \\
\text { (second mediation). }\end{array}$ \\
\hline County-level urban renewal projects & 1955-1966 & $\begin{array}{l}\text { Counties } \\
\text { (2010 Census) }\end{array}$ & $\begin{array}{l}\text { Richmond Renewing } \\
\text { Inequality(Nelson and Ayers } \\
\text { n.d.). }\end{array}$ & $\begin{array}{l}\text { Calculated as the average in the counties } \\
\text { overlapping with each Census tract. }\end{array}$ \\
\hline $\begin{array}{l}\text { School-district-level index of } \\
\text { concentration at the extremes (ICE): } \\
\text { (Black students - white students) / (Total } \\
\text { students). }\end{array}$ & 1994-1995 & $\begin{array}{l}\text { School districts } \\
(1994-1995)\end{array}$ & $\begin{array}{l}\text { Elementary/Secondary } \\
\text { Information System (U.S. } \\
\text { Department of Education n.d.) }\end{array}$ & $\begin{array}{l}\text { Calculated as the average ICE in the school } \\
\text { districts overlapping with each Census tract. }\end{array}$ \\
\hline Median home value & 2006 & $\begin{array}{l}\text { Tracts } \\
(2010 \text { Census })\end{array}$ & $\begin{array}{l}\text { Zillow Home Value Index } \\
\text { (Zillow 2019). }\end{array}$ & Smoothed and seasonally adjusted. \\
\hline $\begin{array}{l}\text { Index of concentration at the extremes } \\
\text { (ICE): (Black working-class - white } \\
\text { professional class) / (Total population) }\end{array}$ & 2015-2019 & $\begin{array}{l}\text { Tracts } \\
\text { (2010 Census) }\end{array}$ & $\begin{array}{l}\text { 2015-2019 American } \\
\text { Community Survey 5-year } \\
\text { estimates (U.S. Census Bureau } \\
\text { 2020). }\end{array}$ & $\begin{array}{l}\text { Census table-variables: [(C24010B_004 + } \\
\text { C24010B_005 + C24010B_006 + } \\
\text { C24010B_007) - (C24010A_003 + } \\
\text { C24010A_009)] / (C24010_001). }\end{array}$ \\
\hline Period life expectancy & 2018 & $\begin{array}{l}\text { Tracts } \\
(2010 \text { Census })\end{array}$ & $\begin{array}{l}\text { NVSS U.S. Small-area Life } \\
\text { Expectancy Estimates Project } \\
\text { (National Center for Health } \\
\text { Statistics 2018). }\end{array}$ & See Appendix Section 2a. \\
\hline
\end{tabular}




\section{A2. NVSS U.S. Small-Area Life Expectancy Estimates Project (USALEEP) Sensitivity}

Inference based on predicting period life expectancy, which is itself partially based on a parametric small-area model for age-specific mortality rates that includes sociodemographic covariates, may result in conclusions that are partially based on the covariance between our exposures/mediators and those used in that model, rather than solely based on variation in the true underlying mortality rates. The USALEEP estimates are produced by first splitting all Census tracts into two groups: 1) Census tracts with 6-year total population size of 5,000 or more and at least 1 death in all age groups and 2) Census tracts with 6-year total population size of 5,000 or more and 1 or more age groups with zero deaths. Census tracts with a total population size of less than 5,000 are excluded. The next step involves fitting a zero-truncated negative binomial to estimate age-specific mortality in the first group of tracts, which includes the following covariates: region, percentage of Census-tract population that is non-Hispanic Black (quartiles), percentage of Census-tract population that is Hispanic (quartiles), percentage of Census-tract population with a bachelor's degree or higher (quartiles), population density (quartiles), and inside/outside Purchased/Referred Care Service Delivery Areas. The NVSS file includes a flag for each tract to indicate whether period life expectancy estimates are based on age-specific mortality rates that are (1) completely observed $(n=4,413)$, (2) completely predicted $(\mathrm{n}=8,560)$, and (3) a combination of observed and predicted $(\mathrm{n}=52,690)$.

While it is not possible to test empirically, we contend that there are strong reasons to believe that the parametric relations off of which we base our conclusions are primarily the result of the relation between these exposures/mediators and underlying mortality conditions (conditional on all other assumptions stated), rather than simply an artifact of the USASLEEP modelling procedure for certain age-specific mortality rates:

1. We restrict our final sample to exclude tracts in group (2) where period life expectancy is based solely on predicted age-specific mortality rates $(n=8,560)$.

2. Of tracts in group (3), the majority only include predicted age-specific mortality rates in one to three out of the 11 total age groups: "The majority of these census tracts $(89.0 \%)$ had one to three age groups with missing deaths, and $10 \%$ had four or more age groups with missing deaths (Table 4). The majority of census tracts were missing deaths in the $0-1,1-4$, or $5-14$ age categories, at $29.7 \%, 80.9 \%$, and $74.3 \%$, respectively (not mutually exclusive)."

3. The bivariate correlations between life expectancy, redlining grade, and all mediators are very similar between the combined groups (1) and (3) (our analytic sample), and group (1) alone which includes no predicted age-specific mortality rates.

Still, this limitation is difficult to test and is inherent to using the USALEEP estimates as a dependent variable. Ideally, estimates of period life expectancy would be made available to 
researchers that are based solely on observed mortality data and entirely non-parametric smoothing procedures in the case of zero or very low death counts. 